\title{
Treating Psychopaths Fairly
}

\section{Monique Wonderly}

To cite this article: Monique Wonderly (2016) Treating Psychopaths Fairly, AJOB Neuroscience, 7:3, 158-160, DOI: 10.1080/21507740.2016.1218391

To link to this article: http://dx.doi.org/10.1080/21507740.2016.1218391

\section{Published online: 03 Oct 2016.}

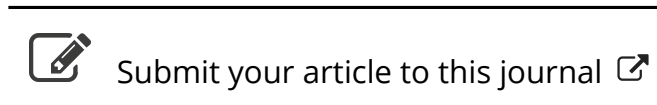

\section{Џ Article views: 50}

Q View related articles $\asymp$

View Crossmark data $\nearrow$ 


\section{REFERENCES}

Carter, J. A., and E. C. Gordon. 2015. On cognitive and moral enhancement: A reply to Savulescu and Persson. Bioethics 29(3): 153-161.

Harris, J. 2011. Moral enhancement and freedom. Bioethics 25(2): $102-111$.

Harris, J. 2013. Moral progress and moral enhancement. Bioethics 27(5): 285-290.

Hübner, D., and L. White. 2016. Neurosurgery for psychopaths? An ethical analysis. AJOB Neuroscience 7(3): 140-149.

Jotterand, F. 2011. "Virtue engineering" and moral agency: Will post-humans still need the virtues? AJOB Neuroscience 2(4): 3-9.
Lev, O. 2012. Enhancing the capacity for moral agency. AJOB Neurosicence 3(4): 20-22.

Nahmias, E. 2011. Intuitions about free will, determinism, and bypassing. In The Oxford handbook of free will, 2nd ed., ed. R. Kane, 555-587. Oxford University Press.

Raus, K., F. Focquaert, M. Schermer, J. Specker, and S. Sterckx. 2014. On defining moral enhancement, a clarificatory taxonomy. Neuroethics 7(3): 263-273.

Rachels, J. 1986. The elements of moral philosophy. Englewood Cliffs, NJ: McGraw-Hill.

Simkulet, W. 2012. On moral enhancement. AJOB Neuroscience 3(4): 17-18.

\section{Treating Psychopaths Fairly}

\section{Monique Wonderly, Princeton University Center for Human Values}

Hübner and White (2016) question the ethical justification of employing risky neurosurgical interventions to treat imprisoned psychopaths. They argue that (1) such interventions would confer no medical benefit on the psychopath as there is no "subjective suffering" involved in psychopathy and (2) psychopaths could not voluntarily consent to such procedures because they could have no "internal motivation" for doing so. The authors insightfully show that certain aspects of the psychopath's personality structure are especially relevant to assessing the ethics of risky treatment options. As I argue, however, the authors' conclusions are too strong. A deeper look at the psychopathic profile casts doubt on both (1) and (2). In some cases, psychopaths can be plausibly construed as experiencing subjective suffering from their disorder and as appropriately motivated to voluntarily consent to neurosurgical treatment. After arguing for this view, I suggest that the psychopaths' consent to neurosurgical intervention might nonetheless be problematic, as their emotional incapacities could preclude their abilities to adequately appreciate the relevant risks.

Hübner and White claim that there is no subjective suffering involved in psychopathy. Contra the authors, I think it is quite possible that psychopaths do, in some sense, suffer from their psychopathy. While psychopaths do not typically lament their antisocial behaviors, they do experience adverse emotions on account of their disorder. For example, psychopathy is associated with heightened levels of frustration and anger (Hare 1993; Blair, Mitchell, and Blair 2005). Such experiences are presumably unpleasant and plausibly construed as a kind of suffering. Importantly, certain features of the psychopath's disorder may impede her ability to convey this suffering in self-reports. These features include fleeting affects and difficulties processing and employing emotional language (Blair, Mitchell, and Blair 2005; Kiehl 2006; Lander, Lutz-Zois, Rye, and Goodnight 2012). While not infrequent, the psychopath's bouts of frustration and severe anger tend to be short-lived and thus generally do not resonate with her for long. This aspect of psychopathy-in addition to a lack of facility with emotional language-might explain why psychopaths do not report their condition as painful despite frequent instances of subjective suffering. Neurosurgical treatment aimed at modifying the psychopath's behavior would likely also reduce the psychopath's own unpleasant experiences of frustration and anger, as these features are likely related. Thus, treatment could subjectively benefit the psychopath and not just her society.

Hübner and White rightly suggest that psychopaths "approve of" their socially unacceptable attitudes and behaviors. Yet, on my view, Hübner and White infer too much from this. They conclude that because psychopaths lack moral motivation to change their behaviors, they cannot be appropriately motivated to opt for treatment in the sense that voluntary consent requires. This reasoning assumes that the only relevant features of the disorder are its associated moral deficits, but importantly, psychopathy also involves features that are inimical to psychopaths' own (nonmoral) interests. In addition to the adverse emotions noted above, psychopaths also have difficulties forming long-term goals, and their more immediate aims are often hindered by impaired capacities for emotional/social learning, discursive incoherence, and poor behavioral controls (Hare 1993; Blair, Mitchell, and Blair 2005; Watson

Address correspondence to Monique Wonderly, Harold T. Shapiro Postdoctoral Research Associate in Bioethics, Princeton University Center for Human Values, 5 Ivy Lane, Rm. 105, Princeton, NJ 08540, USA. E-mail: wonderly@princeton.edu 
2013). Hare (1993) includes "poor behavioral controls" and "lack of realistic long-term goals" among the psychopath's defining traits. Similarly, the psychopath's impaired ability to learn from social/emotional cues makes it more likely that she will repeat mistakes that thwart her own ends (Blair, Mitchell, and Blair 2005). Finally, while psychopaths can be quite charismatic, they are also subject to what Gary Watson refers to as "discursive incoherence" - marked, in part, by an inability to manage one's self-presentation in minimally coherent ways $(2013,287)$. Psychopaths often contradict themselves in speech and shift roles in mid conversation, making it difficult to effectively communicate with others (Watson 2013). This amalgam of features suggests that the disorder impedes the psychopath's own interests. While they may express no interest in moral improvement, psychopaths might still be moved by the prospect of being better positioned to achieve their immediate ends. Neurosurgical treatment aimed at modifying a psychopath's immoral behaviors would likely also attenuate some features of the disorder that hinder her own aims, and she might find it choice-worthy on that account. Though not all psychopaths would reason in this way (especially since they often display a lack of regard for their own interests as well as those of others), some might.

Of course, psychopaths might attribute their personal adversity not to their psychopathy, but rather to society's misunderstanding and "unjust" treatment of them. But even if this is so, it would not preclude the psychopath from being appropriately (internally) motivated to opt for neurosurgical treatment. While the psychopath might regard her disorder itself as a favorable condition, she might reasonably opt for treatment because she recognizes that given the "unfair" structure of her society, her psychopathy hinders certain of her goals-for example, acquiring wealth, achieving power, and so on. For psychopaths, in particular, having their immediate aims satisfied may be more important than retaining the constellation of traits and desires with which they "identify." This is because it is not clear that they are especially attached to their identities in the sense that typical non-psychopathic agents are (Watson 2013). In any case, one's decision to seek treatment might be influenced by one's external circumstances and still not divorced from one's internal motives in a way that undermines voluntary consent.

Consider, for example, a hypothetical case in which a deaf person who regards her deafness as a positive condition (and one with which she strongly identifies) chooses a risky surgery to reverse it because she reasons that, given her unfairly structured society, the ability to hear will confer certain advantages that she values more than retaining her deafness-for example, greater employment prospects that might make it easier to provide for her family. The person in this scenario seems suitably motivated to voluntarily consent to treatment despite viewing her deafness itself as largely positive and as obstructive only in virtue of her societal structure. Likewise, the psychopath (incarcerated or otherwise) might at once both regard her condition as inherently good and opt to have it treated for reasons that are not reducible to the mere desire to avoid social sanctions. The ability to function in one's society in a way that conduces to achieving one's own aims is surely a legitimate consideration when deciding on treatment.

While I question the particular conclusions that Hübner and White draw from their analysis, I agree with their broader point that owing to the psychopath's personality structure, her consent to neurosurgical treatment might be especially problematic. To my mind, however, the problem concerns not the voluntariness of the psychopath's consent, but rather, her ability to adequately appreciate the relevant risks. Treatments that involve manipulating neural structures and/or stimulating (or suppressing) neural activity, if successful, would likely change not only psychopathic behaviors, but also the attitudes and emotions that underlie those behaviors (Hoeprich 2011). Sudden, enhanced emotional awareness can be traumatic. For example, John Elder Robison, whose Asperger's syndrome was treated with transcranial magnetic stimulation, reported an "emotional awakening" following his treatment-but one that "overwhelmed" him, resulted in painful realizations about past events, and ultimately led to the demise of his marriage (Robison 2016). The effects of sudden, enhanced emotional capacities could prove particularly devastating for psychopaths. Psychopaths might not merely have trouble adjusting to the novelty of certain emotions, but they might also come to look upon their previous attitudes and behaviors in a very negative light, resulting in severe emotional pain. Given the psychopath's emotional deficits, and the distinctively emotional nature of the relevant dangers, there is reason to doubt that she could fully appreciate these risks.

Despite my objections to Hübner and White's view, I think that the authors effectively and insightfully raise important concerns about employing risky neurosurgical procedures to treat incarcerated psychopaths. In order to treat psychopaths fairly, we must consider how the particular features of their disorder impact the feasibility of providing medical intervention that meets minimal bioethical standards. Given the preceding discussion, we should, at the very least, exercise extra caution when considering neurosurgery for psychopaths.

\section{REFERENCES}

Blair, J., D. Mitchell, and K. Blair. 2005. The psychopath: Emotion and the brain. Malden, MA: Blackwell.

Hare, R. D. 1993. Without conscience: The disturbing world of the psychopaths among us. New York, NY: Guilford Press.

Hoeprich, M. 2011. An analysis of the proposal of deep brain stimulation for the rehabilitationn of criminal psychopaths. Presentation for the Michigan Association of Neurological Surgeons, June 11. Available at: http://www.destinationmi.com/documents/ 2011MANSpresentation_MarkHoeprich.pdf 
Hübner, D., and L. White. 2016. Neurosurgery for psychopaths? An ethical analysis. AJOB Neuroscience 7(3): 140-149.

Kiehl, K. 2006. A cognitive neuroscience perspective on psychopathy: Evidence for a paralimbic dysfunction. Psychiatry Research 142:107-28.

Lander, G., C. Lutz-Zois, M. Rye, and J. Goodnight. 2012. The differential association between alexithymia and primary versus secondary psychopathy. Personality and Individual Differences 52:45-50.

Robison, J. E. 2016. Switched on: A memoir of brain change and emotional awakening. New York, NY: Spiegel \& Grau.

Watson, G. 2013. Psychopathy and prudential deficits. Proceedings of the Aristotelian Society CXIII(3): 269-92.

\section{An Expanded Understanding of Individual Medical Benefit?}

\section{Dale Murray, University of Wisconsin-Baraboo/Sauk County}

There has been some enthusiasm for the possibility of treating incarcerated psychopaths using deep brain stimulation (DBS) techniques. However, Hübner and White (2016) make a compelling case that incarcerated psychopaths cannot meet the legal and moral requirements of voluntary informed consent to such procedures in principle. Since psychopaths by definition don't care if they are doing anything wrong when they transgress moral or legal boundaries, they do not have internal motivation to agree to research or therapeutic DBS for their condition. This would mean that if incarcerated psychopaths had any motivation to consent to DBS procedures, it would be for external reasons (perhaps for a reduced prison sentence) that would likely constitute undue influence. Since incarcerated psychopaths are members of a vulnerable group (prisoners), external motivations are not sufficient for voluntary informed consent to DBS. With this, Hübner and White make a sufficiently strong case to undermine the idea that incarcerated psychopaths could meet the requirements for voluntary informed consent to DBS.

But Hübner and White make a second claim that is not as clearly substantiated. They argue that incarcerated psychopaths also cannot receive any individual medical benefit from DBS procedures, as they do not suffer from their condition. That is, psychopaths do not perceive themselves as having any problem at all-in fact, they seem quite content with their condition. Because incarcerated psychopaths are part of a vulnerable group that has been exploited before in research and clinical procedures, the threshold for individual medical benefit is high. Thus, for all prisoners what qualifies as individual medical benefit needs to be direct and subjective. The definition of individual medical benefit for incarcerated psychopaths (as for all other inmates) thus requires that they detect in their subjective experience suffering that treatment or research protocols have a reasonable chance of remedying. However, since incarcerated psychopaths don't in fact experience such suffering, they would not receive individual medical benefit and thus not qualify for therapeutic or research DBS.

On the one hand, Hübner and White worry that psychopathy is too "medicalized" - that it isn't something from which one can really be cured because it isn't really a disease, but instead a configuration of socially unacceptable traits. (I realize they say that for the sake of argument they accept psychopathy as an ailment.) However, Hübner and White also anticipate the objection that their focus is too much on medical research and therapy, while proposed DBS for psychopaths might be considered a "moral enhancement" instead of a medical intervention. Curiously, Hübner and White retort that they would worry about such "de-medicalization" of psychopathy. It's unclear how Hübner and White can consistently hold both of these stances. It would be useful to know how they would (definitively) classify psychopathy-presumably it can't be a medical and nonmedical condition simultaneously, so which is it?

Also, it is unclear why removing the distress of the imposition of social sanctions wouldn't be enough to qualify as an individual medical benefit. How do we distinguish the distress of a psychopath who is incarcerated from her subjective suffering? Even if this "distress" isn't an example of subjective suffering, it will likely be experienced as some sort of impediment, perhaps to her autonomy. After all, incarcerated psychopaths are experiencing something that causes them to desire freedom over incarceration.

But beyond that, Hübner and White could be correct that incarcerated psychopaths can't subjectively suffer from their condition. This leaves us with an intriguing normative question. Should subjective individual medical benefit necessarily be the sole criterion for medical benefit for any prisoner? Why can't other types of individual benefit qualify as medical benefit, at least to the extent that a condition can be treated? After all, when physicians strive

Address correspondence to Dale Murray, Associate Professor, Department of Philosophy, University of Wisconsin-Baraboo/Sauk County, 1006 Connie Rd., Baraboo, MI 53913, USA. E-mail: dale.murray@uwc.edu 